\title{
Observations on Appropriate Technology Application in Indigenous Community Using System Dynamics Modelling
}

\author{
Paulus Daniel Jokhu and Cat Kutay * \\ Faculty of Engineering and IT, University of Technology, Sydney 2006, Australia; \\ paulus.daniel@alumni.uts.edu.au \\ * Correspondence: cat.kutay@uts.edu.au
}

Received: 1 February 2020; Accepted: 4 March 2020; Published: 13 March 2020

check for updates

\begin{abstract}
It is possible to develop a well-sustained society by balancing social, technical, and environmental concerns at the community level. Indigenous governance methods provide enormous prospects for developing well-sustained societies. A limitation is the knowledge gap and lack of interest from dominant cultures. With the application of appropriate technology in development, it is possible for Indigenous communities to adjust technology to their uses and transfer their accumulated knowledge to the development of infrastructure and mechanisms for production incorporating cultural value. Activating such talents within the Indigenous community is important for enabling them to achieve their ideal future. Using participatory design methods, Indigenous people can be brought into the development planning to understand the key variables that limit and influence technology development. System dynamic modelling can be adapted to simulate these new attributes and develop plans and objectives based on outcomes from the model. An example is shown around a case study for community development in Papua, Indonesia. This research is to establish a long-term development plan for all stakeholders, while preserving the value of the Indigenous culture. An analysis of Indigenous social behavioral patterns toward development provides an idea of social-constructive values, which will allow Indigenous community to develop self-sustainable and independent communities.
\end{abstract}

Keywords: modelling development; indigenous co-design; participation in development

\section{Introduction}

The development of society is strongly influenced by the background and environment of its development. Modern society is growing rapidly, which seems to contrast with Indigenous communities. Their growth in the last century seemed slow or even stagnant. The link between the community background and their readiness to follow the development of technology promotes the need for accurate guidance to describe what kind of technology is needed by an Indigenous community to enable adaption to technological advances and prevent stagnation.

Innovation in technology creates several possibilities for the future of Indigenous communities. Developing societies tend to focus on one purpose, namely the advancement of lifestyle in terms of productivity. For a developing society, technology can even be a weapon that is harmful toward them, for instance the growing pressure for multi-tasking. Therefore, these technologies are often not taken up in Indigenous communities, who can see these effects observed from the outside. There is little reason for developing societies to provide technology specifically for an emerging society.

The most common reason for lack of technology in a community is an inability to maintain and operate this without prior experience, and the lack of resources for the technology to be maintained. 
One interesting example is the recent news that Microsoft donated computers to one of the schools in Ghana, West Africa after one of the teachers went viral because he taught Microsoft Word by drawing the user interface using their blackboard, concerned that students learn the system as it provides access to many jobs [1].

It can be seen how it takes a long time for villages to adapt to new technology. Effort to engage with foreign developed technology can become a waste and in time cause harm to the community. However, if integrated into community values and culture, a technology can become a milestone for a new era within that Indigenous community [2]. We look at developing a framework to design the introduction of technology through community consultation. The understanding gained by consultation provides the key variables for modelling possible outcomes. These can be presented as options to the people, options based on outcomes that match the expressed needs and existing circumstances of the community, or as strategies to direct development in a planned manner. By using a dynamic model, we can vary the system to match the community variables and display options that relate to the community aspirations and actual present state.

\section{Literature Review}

While many claim growth and sustainability are incompatible [3], ecological economists have tried to incorporate sustainable development through the concept of natural capital in ecological economics [4], while Indigenous groups continue to have to justify their wellbeing projects through economic factors [5]. Economists and policy makers have acknowledged that institutions, social relationships, and cultural matters have a role in development by evaluating projects using the triple bottom line.

Such work has ignored attempts by indigenous peoples, particularly within advanced societies, to articulate their own self-determined development. Throsby and Petetskaya [6] note that "land has a spiritual, social, cultural, economic, and political significance to Indigenous communities that derives from deeply held spiritual beliefs". This generates a series of responsibilities and obligations for individuals that embed sustainable practices into the life of Indigenous communities. Non-Indigenous responsibility tends to rely more on government policy and practice coordinated by the UN World Commission on Environment and Development.

As globalization is the main cause of recent rapid development of technology and cultural exchange around the world, it results in creating a commonality of needs and aspirations across regions that ignores individual cultural aspirations. Globalization has pros and cons in terms of social, economic, and political impacts [7], and only a small portion of culture heritage survives in some way [8] due to its effects.

In Asmat, Papua, Indonesia, the people have organized to oppose the effect of logging and fishing by external organizations, which removes their livelihood. The influx of foreigners from other Indonesian islands into the traditional culture and the displacement of Indigenous people from regions being developed for external industry is causing disruption. The Indigenous focus on community life is not shared, and the ability to practice their sustainable economics is disrupted. With the loss of forests and the increasing distance to collect food staples, the Asmat people are relying on western foods. Much of the area is dependent on government subsidy money in the form of general funds allocation (IPAC) [9]. Abuse of the funds by distributors often means many villagers do not receive their fair share.

Indigenous people can establish a well-developed and sustainable environment as long as the appropriate approach and method is used, sufficient background to the technology is explained [9], and adaption is encouraged [10,11]. At the Centre for Appropriate Technology in Alice Springs, Australia, there is a model offered to adjust technology to suit the culture and respect the Indigenous history [12]. Furthermore, the model can be applied for town planning and concept design without disregarding the aesthetic and cultural value. 
As Sibanda [13] mentioned in his case studies in Zimbabwe, Indigenous knowledge in developing communities is a growth agent toward well-being of the community, and Indigenous natural resource management systems are being incorporated into mainstream analysis [14]. Furthermore, studies show that Indigenous knowledge is far more sophisticated than previously assumed and use of the Indigenous knowledge system (IKS) is on par with the Western knowledge system. IKS's main limitation is the use of oral communication, which leads to lack of written scientific procedures that are the assumed method of objectifying knowledge.

Lack of interest from the young generation could cause Indigenous knowledge erosion. Based on the Zimbabwe case study [13], for example, the young generation found that IKS appeared to be obsolete and out of date compared to Western cultural knowledge and practices.

Akubue [15] focused on cases within an Indigenous community in developing countries. When improvement of technology occurs through transfer from developed nations, there is a negative impact towards the environment. While many agree that the purpose of technology improvement is simplification, which improves the efficacy in workspace and method, this will not have a widespread effect in a country without large capital resources and will impact on the level of pollution. This creates a paradox for technology improvement. In one case, it will satisfy the needs of many people's personal lives but it will exploit the environment.

Ernst Friedrich Schumacher was considered as the founder of the appropriate technology movement with his book Small is Beautiful [16]. The primary purpose of this technology is for sustainable and environmental control, especially in developing regions, and has been taken up by many other writers e.g., Thormann [17] and Akubue [15]. Furthermore, Pellegrini [18] highlighted the necessity that appropriate technology should have the capacity to be self-sustained by its user. Multiple layers of standards should be achieved for a technology to be considered as an appropriate technology, which many appropriate technologists establish in some of their writings.

Work by Indigenous people across the world to share approaches to technology and development processes are opening alternative options for development. Morgan et al. [19] utilized a Mauri framework to apply to engineering case studies to assess problem-solving in complexity. This framework measures four dimensions of wellbeing as the basis of assessing project sustainability, namely "the mauri of community (social), the mauri of whänau or family unit (economic), the mauri of the ecosystem (environment), and the mauri of hapü (culture)" (Wambrauw \& Morgan [20]) and closely aligns with the aspirations of the people of Asmat in Papua, Indonesia.

\section{Material and Methods}

This research is based on a case study developed around a significant technological project planned for development in Papua. Initial data was collected during construction design work with the Local Aboriginal Lands Council (LALC) in NSW, Australia, as the sample for comparison. In determining suitable approaches for a solution to address the problems in development for the Indigenous community, we used participatory modeling.

There are many tools in addressing matters for stakeholders where ideas can be shared altogether, implicitly and explicitly. All participant can address the problem subjectively by combining these views through interactions. This can isolate biases that occur from individual observation of the problem. With participatory modeling, every idea, piece of information, and the decision can be openly justified based on each bias and limitation to tackle any gaps in each decision [21].

Participatory action research (PAR) is a community-based study, or co-operative inquiry, based on action research. Prioritizing people and their reaction towards specific processes have worked in the medical field to assist health workers to evaluate the appropriate method for a client [22-25].

Hopkins [26] defines action research as following standard research procedures while supporting inquiry and a personal attempt not only to understand but also able to improve and reform the people or area under study. As Winter and Munn-Gidding [27] highlight, the involvement of the researchers 
and the participants in a coherent progress of the research improves both practice and quality of their understanding.

For this project we used this research method for technology sharing around the development of Indigenous communities through accumulated quantitative data for constructing an appropriate model to simulate the well-being of an Indigenous community based on their collective and sustainable priorities. Survey and data gathering were conducted along with brainstorming with stakeholders in defining all the possible case scenarios and their impacts toward related variables in development progress. This provided the generation of the model for future planning proposed with communities in Papua.

We discuss now the process that arose from this case study as a framework for community development and describe how the model was defined and the scenario tested. This includes the consultation steps and the types of factors that arise from research with stakeholders from an Indigenous community. These factors are considered for their impact on development projects to verify the model.

The participatory modelling (PM) approach is the basis of this framework, although there are several alternatives paths that can be considered. The availability and applicability of each method also heavily depend on circumstances and the stakeholder engagement with the problem and skills they bring already. However, the overall aim is to ensure a process is created for long-term, durable, and positive change from the outcomes of the project [28]. One change is to incorporate technology engagement into the community for maintenance and the dispersion of the technology to other communities through those who have been skilled up [29-31]. There are many processes where community can be engaged (see Figure 1).

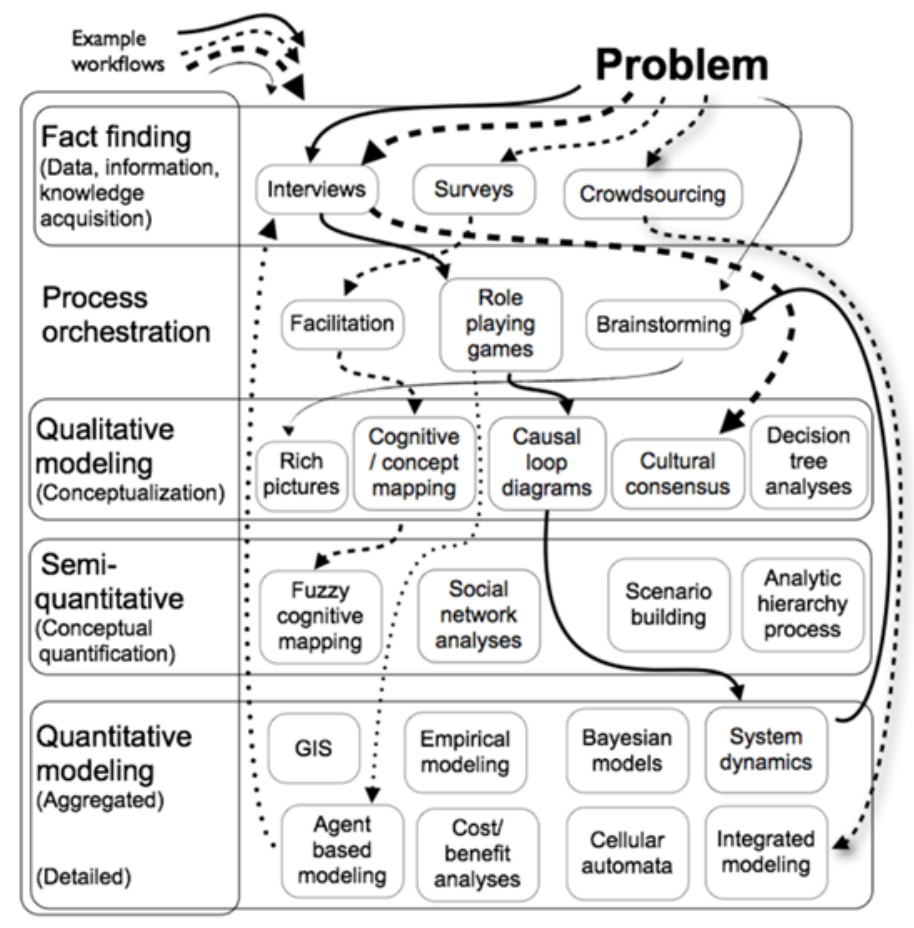

Figure 1. Typology of methods used in participatory modelling (PM) with example workflows [31].

\section{Data Modelling}

To link these into a system model, data gathering was used to evaluate the local values of affiliation factors for each variable (listed for the model in Table 1). This was conducted by visiting the location of the Indigenous community to be involved in the project. From the attributes extracted in these initial discussions, the interview or survey was developed and conducted. The participants were asked about each of the variables to verify their importance or value in the development model for their project. 
As found in the case study experience, we recommend having a community champion or organization CEO distribute these questionnaires.

Table 1. Applied function in Vensim for simulating dynamic model of sample based on Miniworld3 with modifications.

\begin{tabular}{|c|c|c|c|c|}
\hline $\mathbf{N}$ & Type & Notation & Variables & Variable Relation Equation \\
\hline 1. & a & $t_{a}$ & application time & 120 \\
\hline 2. & c & ATA & appropriate technology application & $U_{1} \times Q_{t c}$ \\
\hline 43 & a & $B_{c}$ & birth control & $3<0$ \\
\hline 4. & $\mathrm{~b}$ & $B_{r}$ & birth rate & $0.03+R A N D O M U_{N} I F O R M^{(a)}(0,0.1,999)$ \\
\hline 5. & $\mathrm{~b}$ & $B$ & births & $B_{r} \times C_{l v} \times B_{c} \times Q_{e} \times W$ \\
\hline 6. & a & C & capacity & 10 \\
\hline 7. & $\mathrm{~b}$ & $C_{i}$ & capacity increase & $\operatorname{DELAY3^{(c)}}\left(G_{r} \times C_{l v} \times E P, 12\right) \times\left(1-\left(C_{l v} \times E P / C_{g}\right)\right)$ \\
\hline 8. & a & $C_{g}$ & consumption goal & 10 \\
\hline 9. & c & $C_{l v}^{\delta}$ & consumption level & $P C \times W$ \\
\hline 10. & $\mathrm{~b}$ & $D$ & degradation & $D_{r} \times P \times C_{l v} / A T A$ \\
\hline 11. & a & $D_{r}$ & degradation rate & 0.02 \\
\hline 12. & a & $D_{t}$ & damage threshold & 1 \\
\hline 13. & a & $F_{r}$ & death rate & 0.05 \\
\hline 14. & c & $F$ & deaths & $D_{r} \times E P$ \\
\hline 15. & c & $E P$ & Environment Pollution & $\left(D_{r}-R\right)$ \\
\hline 16. & a & $G_{r}$ & growth rate & 0.05 \\
\hline 17. & a & $I_{h}$ & housing & 0.2 \\
\hline 18. & c & $I_{e}$ & infrastructure establishment & $I_{h} \times P \times W+I_{t c}$ \\
\hline 19. & c & $I_{t c}$ & training center & $U_{0} / C$ \\
\hline 20. & c & $L U$ & land usage & $A-I_{e}$ \\
\hline 21. & c & $P$ & population & SMOOTH3 $^{(\mathrm{e})}((B-F), 12)$ \\
\hline 22. & a & $P C$ & production capacity & $C_{i}$ \\
\hline 23. & c & $Q_{e}$ & quality of environment & $D_{t} \times E P$ \\
\hline 24. & a & $Q_{t c}$ & training quality & 0.7 \\
\hline 25. & $\mathrm{~b}$ & $R$ & regeneration & $\begin{array}{l}\operatorname{IF} T H E N \operatorname{ELSE}^{(f)}\left(\operatorname{DELAYY}^{(d)}\left(Q_{e}, 20\right)>\right. \\
\left.1, R_{r} \times E P, R_{r} \times D_{t}\right)\end{array}$ \\
\hline 26. & a & $R_{r}$ & regeneration rate & 0.1 \\
\hline 27. & a & $W$ & society wellbeing & 1 \\
\hline 28. & c & $T W$ & training and workshops & $\left(U_{0} / I_{t c}-U_{1}\right)$ \\
\hline 29. & c & $U_{1}$ & articulate users & $\operatorname{DELAY1} 1 I^{(\mathrm{a})}\left(T W, t_{a}, 0\right)$ \\
\hline 30. & $\mathrm{~b}$ & $U_{0}$ & non-articulate users & $\operatorname{DELAY1}^{(\mathrm{d})}(P, 20)$ \\
\hline
\end{tabular}

Note: (a): Delay for subjected variables occurs in accordance with progression flow $(\mathrm{t})=\mathrm{t}_{\mathrm{a}}$; and with initiation time constrain $(c)=0$. (b): Complex modelling of birth rate value over time. With $(n)=999$, variances over time. (c): Delay that occurs for subjected variables will restrict the progression flow of the subjected variables. Hence, no outflow occurs during delay time $(t)=12$. $(d)$ : Delay for subjected variables occurs in accordance with progression flow $(t)=20$. (e): Adjusted flow for subjected parameter to restricting sudden drop rate. (f): Logical function in defining two alternate outcomes depend on its predecessor value.

We clustered data samples based on age group due to different approaches across generations. The first age group was below 18 years, the second age group was between 19 and 25 years, and the third age group was above 26 years. These variations of the sample are required to cover the subjectivity of individual judgment and understanding regarding the questionnaire's objectives.

To show the relation between each variable we visualized the actual cases through brainstorming with both parties (stakeholder and engineers) to create scenarios where different situations or conditions could be considered, which framed the modeling of the actual condition in a mathematical model.

For modelling the system as analyzed through community meetings, we considered system dynamic modelling (SDM), which was deemed adequate to identify and simulate a problem by addressing the relation between variables that can be observed by both engineers and stakeholders. In identifying each variable and its affiliation towards each other, SDM has proven to be a powerful tool that enables the delivery of necessary information and recommendations when defined variables and its connections are well identified.

The World 3 model was developed by the Club of Rome study to consider the relations between such factors as population increase, agricultural production, non-renewable resource depletion, industrial output, and pollution for analyzing limits in the ecosystems of the earth [32]. While providing fairly good general predictions of the future for the world given the present growth scenario, this model's 
drawback is that it can only simulates the possibilities. This means that the certainty of the outcome is not guaranteed

The model proposed is a scaled down version of World3 based on a miniworld described by Bossel [33], who shows its results are interestingly consistent with World3. While World3 contains many more state variables, parameters, and equations, it is the simplicity, robustness, and reliability of the Miniworld model that was considered sufficient for these simulations.

In determining the important variables, there are multiple ways to assessing the important variables and their relations within the observed society. One of the methods used for this is brainstorming. This was conducted with the LALC Management Committee as a practice of the method. Both stakeholder and engineers together shared their knowledge and ideas to address the problem and states that they were currently in, while objectively delivering their judgment to identify which variables were and were not considered important. Judged by both parties, this method could tackle the biases that may occur when this method is conducted individually.

The stock flow diagram model (Figure 2) was then used to link all the variables and their relations affecting the production and environment within the Indigenous community. The main factor should be determining the links and affiliation factors for each variable by correlating the detail of the survey and determining the links for each variable to visualize actual cases. Vensim [34] is a simulation tool for system dynamics modelling that can be adapted to visualize actual cases from data collected and display the relation between population, production, and environment over time. The looping model for using Vensim can be visualized, as seen in Figure 4, to show the system dynamics.

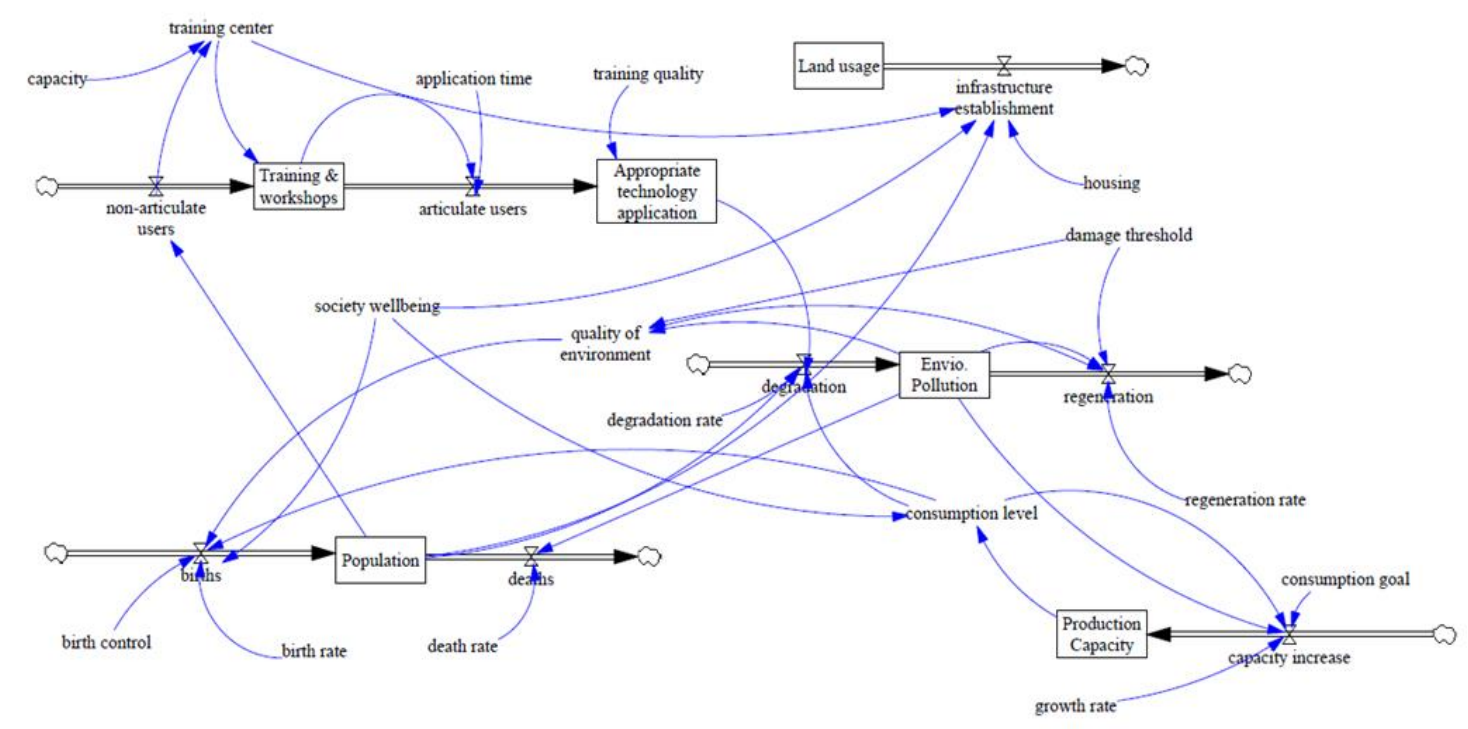

Figure 2. Stock flow diagram simulated using Vensim.

\section{Results}

The interactions located when constructing this model were quite similar to those in the essay written 200 years ago by Malthus in "Essay on the Principle of Population" [35]. If the population growth of any community is not managed accordingly, the population will be decimated by pollution and disease. The after effect of overpopulation that we might face is the disintegration of the whole system.

With the introduction of appropriate technology as the media to correlate the growth of population to the limitation from land usage in terms of occupancy and population expansion, this could limit the pollution emitted from unsustainable technology. Additionally, by using appropriate technology, there is a possibility that the Indigenous community will be able sustain its cultural identity within the colonization process of westernized technology. 
For example, one aspect of humanitarian projects is the focus on the use of available local resources and local manpower. That is only possible if both parties, the community, and technical people can work with the same vision and purpose.

How well a society is able to manage the technology will determine the outcome of technical change and its influence on the way a society lives. The primary concern is that an industrial future creates attitudes that are sweeping away too many traditions that maintain the stability within the society; hence, ethnic deformation occurs.

The variable types are as follows:

a. Considered as natural values. They can be adjusted based on users demand or if there is any necessary requirement for the model to be constructed in specific design. These are adjusted based on the sample behavior

b. Defined as critical formula of the system. This formula was added from the Miniworld 3.0 model by the Club of Rome. Some of the values are here adjusted to correlate with the observed sample behavior but only a small amount so the actual system is able to run close to the Miniworld 3.0 model.

c. Constructed based on the sample behavior established from the survey that was conducted in the sample project, including direct survey and data survey.

A modified version of the Miniworld 3.0 model described here was used for simulations. This model prioritizes not only population, environment pollution, and production capacity but also introduces two variables for improving and restricting growth, which are appropriate technology application and land usage, as well as modifying the user engagement through training and workshops as a community-based education.

All the key variables will be used as the main parameters in initial consultations with each community development project to ascertain the flow of these variables for the model of this specific community.

In this model, appropriate technology application (ATA) can be identified as the amount of functioning technology used in the community. Its emergence arises from the increasing number of users, which relates to the establishment of educational variables in the society. In practice, the aim is to have the educational variable include engagement in such appropriate projects that engage the community in learning about and understanding the technology.

Production capacity (PC) variables are identified as leading factors in economic growth. This variable relates to the decreasing of capacity engaged in appropriate technology and the focusing on the high end market of production. Additionally, the capacity increase variable is related to environment pollution (EP). Kim [36] shows strong scientific evidence regarding the environment reaction in non-linear ways toward $\mathrm{CO}_{2}$ concentration.

Environmental pollution (EP) defines the exposure level of natural habitats with human products of pollution. This variable is influenced by both population $(\mathrm{P})$ and production capacity (PC). Rockstrom [37] claims that industrialized agriculture leads to environmental changes that are able to stabilize human development. However, the relation between population and pollution makes this model often unstable.

Land usage (LU) can be identified with the total area available for the society in term of agricultural purpose, accommodation purpose, and educational purpose. This explains the rapid decreasing of LU in the last estimated period (50-60 years). This rapid change also affects EP, whereas the threshold level is increasing exponentially around that period of estimated time. This result is coherent with nine threshold levels in Holocene Earth processes [37].

Rockstorm [37] adds that if by any chance the threshold is surpassed, the subsystems will shift into different states. The hypothesis is that there will be severe effects on pollution level and land usage if by any chance the society is over-exposed with technologies (the negative effect of the over-used technology in society). 
All five key variables discussed above are shown in Figures 3-7 below. From these graphs, 60 years is considered as a pivot for development adjustment. The relation between five key variables suggests that LU initiates the phase shift for the next upcoming years. $L U=0$ initiates four other key variables to adjusting this threshold. PC shows exponential growth in alignment with EP, which increases gradually, and $\mathrm{P}$ starts to adjust its growth rate at that point.

For the analysis and due to the complexity of interconnectedness in the model, we simplified the system behavior to runs of the model at 5, 10, and 15 capacity values.

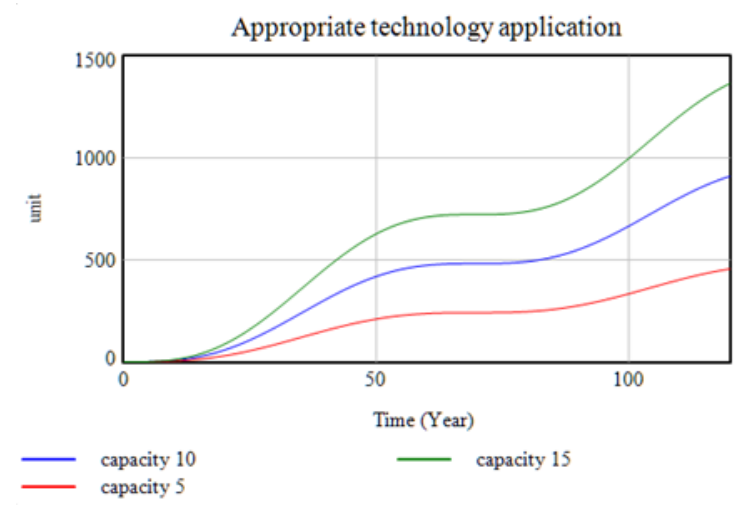

Figure 3. Appropriate technology usage over time based on engagement capacity.

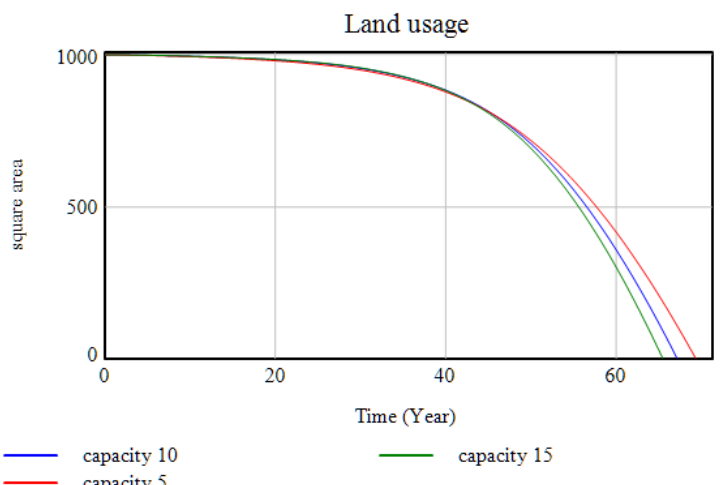

Figure 4. Land usage over time based on engagement capacity.

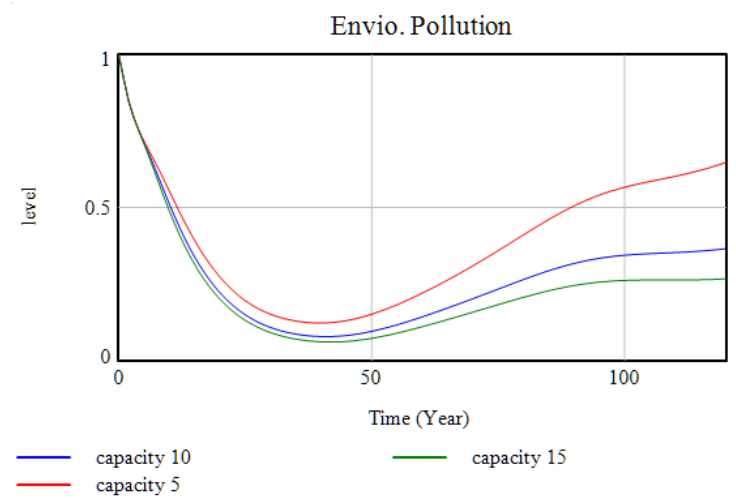

Figure 5. Environmental Pollution created over time based on engagement capacity. 


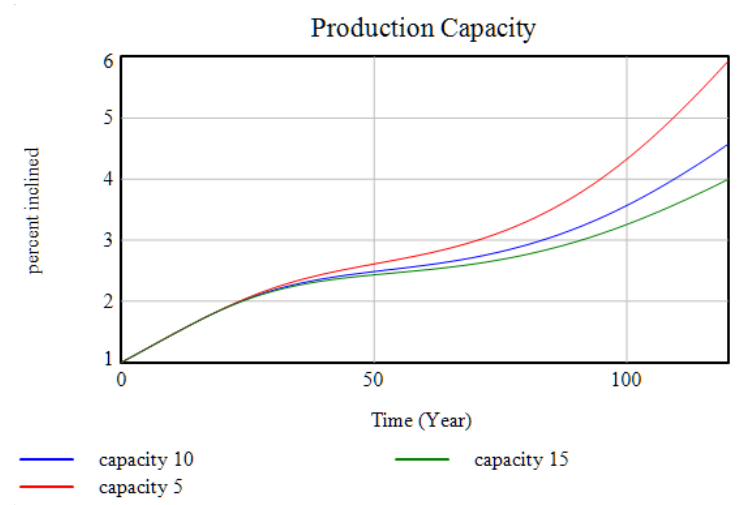

Figure 6. Production capacity over time based on engagement capacity.

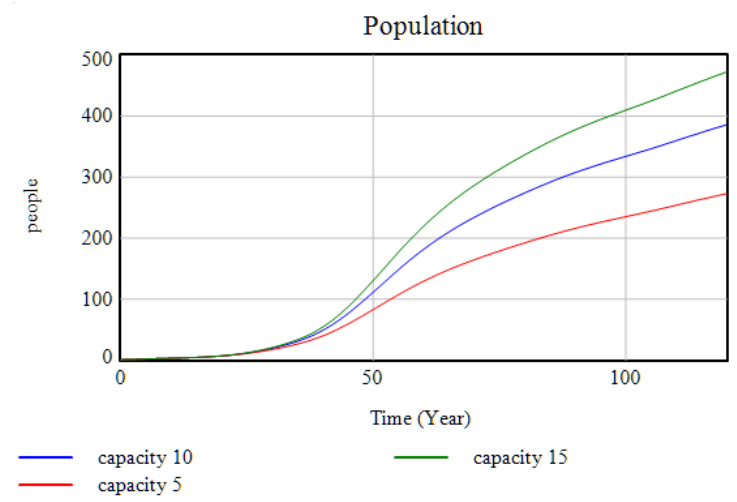

Figure 7. Population over time based on engagement capacity.

\section{Discussion}

We looked at the effect of variations in the model on specific parameters. In particular we are interested in the effect of the capacity of the community to provide people to engage with the technology, and overcome the hurdles of lack of prior education, conflict with cultural aspects, and other factors such as health.

This model is a simplified analysis but provides some understanding of how factors are dependent on each other. For example, in all variables the lower capacity for appropriate technology leads to increased effects on environment and reduced population. Hence the desire is to increase this key variable.

In the practical field of research, we saw a mutual understanding achieved between the community and technical parties through consultation and local based training workshops involving both parties. Engineers began to realize the actual needs inside society born from establishing understanding and empathy. The action taken to resolve the problem within the community does not come from technical point of view, but from the community itself. Engineers work on the process to provide the advice and expertise for the community to reach the desired solution.

The model based on the priorities expressed by the community allows the engineers to show some of the complexity of the proposal options in subsequent workshops. This allows the community some engagement with choice over the design or implementation of projects and in the establishing of priorities. Perhaps the most difficult aspect of technology transfer or co-design of the technology with community is the understanding of the limitations and flexibility in the materials and resources provided to the community.

Understanding what the necessary or key factors are for those who work with the community is important, and these can be gathered by participatory methods. However, it is only by modelling these that the engineers can explain the interdependence of factors in a manner that is relevant to 
community desired outcomes. The system dynamic model is a methodological approach that is able to resolve this gap.

The result gained from the modified model when based on the actual condition in a community and gained through consultation will act as a recommendation towards the appropriateness of the application of defined technology or selected approaches by the community. The model itself will be based on the feasibility studies to establish the suitable parameters of the model in population, industries, and environment quality.

\section{Conclusions}

With this approach, a technologist's viewpoint can lean more towards social and sustainable energy. For humanitarian engineers who have worked in the field largely within the Indigenous community, this report can provide valuable information to learn and establish mutual understanding of the important factors in technology development between technical parties and society with whom they work.

In this research, by using an Aboriginal NSW coastal community as the sample study, and a miniworld variation to model the parameters isolated in this study, we conclude the application of appropriate technology is limited by the number of users engaged in the project, which is described as capacity in the model. It is important to maintain and gradually improve the capacity in a community. Then the environmental and the social pressure will control the amount of self-regenerating agency within the community for conducting technology transfer to increase this capacity. Furthermore, it will also benefit the society in term of environment control over land use and pollution and provide job opportunities for locals, which will improve the economic growth.

\section{Research's Note}

In the academic field, this report can support prior research to establish the relationship between social and technological fields. By opening a new paradigm in the technical studies around society improvement and their relationship with technology, this project will contribute into the expansion of the available academic materials in empirical studies on Indigenous knowledge and society.

Author Contributions: Mr. P.D.J. provided the modelling work and calculations based on analysis of his community in Papua. His studies included researching and utilizing mathematical models of development as well as running a survey with a community in Australia to understand and develop a suitable process of participatory design. Dr. C.K. provided background research linking the Papuan analysis to work with the Local Aboriginal Lands Councils in NSW, Australia and edited the document. She provided advice on the history of this process and cultural aspects of the model design. All authors have read and agreed to the published version of the manuscript.

Funding: This research received no external funding.

Acknowledgments: We thank Alexey Voinov (UTS FEIT Distinguished Professor) for allowing us to use the dynamic model for this research project and providing necessary literature that solved many flaws of the proposed research project. We thank some of the leading teachers in their respective discipline (William Raffle, Jan Golembiewski, Lisa Andersen), for our discussion regarding establishing a model, some related key variables, and methods to collecting data influenced this research in some ways. Thanks to the LALC that allowed us to come and to conduct observation of their governance procedures.

Conflicts of Interest: The authors declare no conflict of interest.

\section{References}

1. Gianluca Mezzofiore, CNN. Donors Give Computers to Ghana School Where Teacher Taught Computer Tech on a Blackboard. 2018. Available online: https://edition.cnn.com/2018/03/15/africa/ghanaian-ict-teacherdonations-intl/index.html (accessed on 9 June 2019).

2. Gado, A. Myths of digital technology in Africa: Leapfrogging development? Glob. Media Commun. 2005, 1, 339.

3. O'Connor, M. (Ed.) Is Capitalism Sustainable? Political Economy and the Politics of Ecology; Guilford: New York, NY, USA, 1994. 
4. Tisdell, C. The Nature of Ecological and Environmental Economics and Its Growing Importance; Working Paper No. 186; University of Queensland: Brisbane, Australia, 2012.

5. Loomis, T. Indigenous Populations and Sustainable Development: Building on Indigenous Approaches to Holistic, Self-Determined Development. World Dev. 2000, 28, 893-910. [CrossRef]

6. Throsby, D.; Petetskaya, E. Sustainability Concepts in Indigenous and Non-Indigenous Cultures. Int. J. Cult. Prop. 2016, 23, 119-140. [CrossRef]

7. Bishop, T.; Reinke, J.; Adams, T. Globalization: Trends mad perspectives. J. Int. Bus. Res. 2011, 10, 117-130.

8. Strongman, L. Reconstruction-An Introduction to International Development Studies. Political Sciences and History; Nova Science Publisher, Inc.: New York, NY, USA, 2018.

9. Downing, J.H. A Report on Traditional Aboriginal Camp Layout about Town Planning April 1974. Natl. J. Teach. Aborig. 1974, 2, 24-34.

10. IPAC. Carving up Papua: More Districts, More Trouble, 9 October 2013 IPAC Report No.3. 2013. Available online: http://file.understandingconflict.org/file/2013/10/IPAC_Carving_Up_Papua_More_Districts_More_ Problems.pdf (accessed on 1 December 2019).

11. Breidlid, A. Culture, indigenous knowledge systems and sustainable development: A critical view of education in an African context. Int. J. Educ. Dev. 2009, 29, 140-148. [CrossRef]

12. CfAT. Available online: https://cfat.org.au/ (accessed on 10 October 2019).

13. Sibanda, H. Sustainable Indigenous Knowledge Systems in Agriculture in Zimbabwe's Rural Areas of Matabelel and North and South Provinces: Zimbabwe Case Study; World Bank: Washington, DC, USA, 1998.

14. Leonard, S.; Parsons, M.; Olawsky, K.; Kofod, F. The Role of Culture and Traditional Knowledge in Climate Change Adaptation: Insights from East Kimberley, Australia. Glob. Environ. Chang. 2013, 23, 623-632. [CrossRef]

15. Akubue, A. Appropriate Technology for Socioeconomic Development in Third World Countries. Journal of Technology Studies: Appropriate Technology for Socioeconomic Development in Third World Countries. Available online: https://scholar.lib.vt.edu/ejournals/JOTS/Winter-Spring-2000/akabue.html (accessed on 10 October 2019).

16. Schumacher, E.F. Small Is Beautiful: A Study of Ecomonics as if People Mattered; Vintage: London, UK, 1973.

17. Thormann, P. Proposal for a program in appropriate technology. In Appropriate Technologies for Third World Development; St. Martin's Press: New York, NY, USA, 1979; pp. 280-299.

18. Pellegrini, U. The Problem of Appropriate Technology. In Criteria for Selecting Appropriate Technologies Under Different Cultural, Technical and Social Conditions; Elsevier: Amsterdam, The Netherlands, 1980; pp. 1-5.

19. Morgan, T.K.K.B.; Sardelic, D.N.; Waretini, A.F. The Three Gorges project: How sustainable? J. Hydrol. 2012, 460-461, 1-12. [CrossRef]

20. Wambrauw, E.V.; Morgan, T.K.K.B. Concept alignment for sustainability: Relevance of the Mauri Model in Asmat, Southern Papua. Altern. Int. J. Indig. Peoples 2014, 10, 288-302. [CrossRef]

21. Voinov, A.; Seppelt, R.; Reis, S.; Nabel, J.E.M.S.; Shokravi, S. Values in Socio-Environmental Modelling: Persuasion for Action or Excuse for Inaction. Environ. Model. Softw. 2014, 53, 207-212. [CrossRef]

22. Koshy, E.; Koshy, V. Waterman, H. Action Research in Healthcare; Sage Publications: Thousand Oaks, CA, USA, 2011.

23. Lingard, L.; Albert, M.; Levinson, W. Grounded theory, mixed methods, and action research. BMJ 2008, 337, a567. [CrossRef] [PubMed]

24. Whitehead, D.; Taket, A.; Smith, P. Action research in health promotion. Health Educ. J. 2003, 62, 5-22. [CrossRef]

25. Parkin, P. Managing Change in Healthcare: Using Action Research; Sage Publications: Thousand Oaks, CA, USA, 2009. [CrossRef]

26. Hopkins, D.; Ahtaridou, E. A Teacher's Guide to Classroom Research; McGraw-Hill: New York, NY, USA, 1993.

27. Winter, R.; Munn-Giddings, C. A Handbook for Action Research in Health and Social Care; Routledge: London, UK, 2001.

28. Poderi, G.; Dittrich, Y. Participatory design and sustainability: A literature review of PDC proceedings. In Proceedings of the 15th Participatory Design Conference: Short Papers, Situated Actions, Workshops and Tutorial, Hesselt \& Genk, Belgium, 20-24 August 2018; pp. 1-5. [CrossRef] 
29. Petra, B.; Elaine, M.; Julia, M.; Galathi, D.; Shirley, N.; Silvia, W.; Marrayurra, W.; Skinner, T.; Campbell, A.; Lowell, A.; et al. Working together with remote Indigenous communities to facilitate adapting to using energy wisely: Barriers and enablers. Energy Proced. 2017, 122, 262-269.

30. Jackson, M.; Stewart, R.; Beal, C. Identifying and Overcoming Barriers to Collaborative Sustainable Water Governance in Remote Australian Indigenous Communities. Water 2019, 11, 2410. [CrossRef]

31. Voinov, A.; Jenni, K.; Gray, S.A.; Kolagani, N.; Glynn, P.; Bommel, P.; Prell, C.; Zellner, M.L.; Paolisso, M.; Jordan, R.C.; et al. Tools and Methods in Participatory Modeling: Selecting the Right Tool for The Job. Environ. Model. Softw. 2018, 109, 232-255. [CrossRef]

32. Forrester, J.W.; Forrester, J.W. World Dynamics; Wright Allen Press Cambridge: Cambridge, MA, USA, 1971; p. 59.

33. Bossel, H. Systems and Models: Complexity, Dynamics, Evolution, Sustainability; BoD-Books on Demand: Helsinki, Finland, 2007.

34. Vensim Simulation Software. Available online: https://vensim.com/ (accessed on 10 November 2019).

35. Malthus, T.R. An Essay on the Principle of Population; Oxford World's Classics Reprint: Oxford, UK, 1798; Chapter V; pp. 39-45. Available online: http://www.esp.org/books/malthus/population/malthus.pdf (accessed on 10 September 2019).

36. Kim, R.E. The Nexus Between International Law and Sustainable Development Goals. RECIEL 2016, 25, 15-26. [CrossRef]

37. Rockstörm, J.; Steffen, W.; Noone, K.; Persson, A.; Chapin, F.S., 3rd; Lambin, E.F.; Lenton, T.M.; Scheffer, M.; Folke, C.; Schellnhuber, H.J.; et al. A Safe Operating Space for Humanity. Nature 2009, 7362, 472-474. [CrossRef] [PubMed]

(C) 2020 by the authors. Licensee MDPI, Basel, Switzerland. This article is an open access article distributed under the terms and conditions of the Creative Commons Attribution (CC BY) license (http://creativecommons.org/licenses/by/4.0/). 